\title{
Case Report: Unusual Presentation of Complicated Diverticulitis at Colostomy Site
}

\author{
Sami Al-Asari* and Nam Kyu Kim \\ Department of Surgery, Yonsei University College of Medicine, 50 Yonsei-ro Seodaemun-gu 120-752, Seoul, South \\ Korea
}

\begin{abstract}
: we report a case of a 75 years old male diagnosed on 2006 with a low rectal cancer and operated with an abdominoperineal resection procedure at that time. Since then, he was doing fine with his end colostomy until 29/07/2011, when he was presented with stoma site redness, pain, tenderness and fever with loose stool; the CT scan showed a distal colon and stoma diverticulitis and abscess lateral to stoma; the patient was managed with drainage, soft diet and antibiotic till it resolved and he was discharged home in a healthy condition.
\end{abstract}

Keywords: Diverticulitis, stoma, Colostomy site, CT scan.

\section{INTRODUCTION AND OVERVIEW}

The term diverticular disease refers to a spectrum of clinical presentations associated with the presence of diverticulae, or outpouchings on the colon [1].

A colonic diverticulum is a false diverticulum because it does not contain all layers of the wall [2].

The incidence of diverticulosis increases with age $[1,3]$. In Western countries, it is estimated to be present in approximately $30 \%$ of people of age 60 and $60 \%$ of people older than age 80 [1]. It also increases with the patient who is on NSAID [3-5], low fiber diet [3,6,7], smoking [3,8], opiates $[3,9,10]$, alcohol $[11,12]$ and immunocompromized $[3,13]$.

Diverticulae most often arise in the sigmoid colon but may also be seen in all colonic segments [1,2]. The primary process is thought to be the erosion of the diverticular wall by increased intraluminal pressure or inspissated food particles $[1,2]$.

Diverticulitis refers to the presence of inflammation or infection around a colonic diverticulum. The inflammation is frequently mild, and a small perforation is walled off by pericolic fat and mesentery [2]. This may lead to a localized abscess or, if adjacent organs are involved, a fistula or obstruction $_{2}$ in comparison to the poor containment results in free perforation and peritonitis [2]

\section{CLINICAL CHARACTERISTICS}

The vast majority of patients with diverticulosis are asymptomatic $[1,3]$. When symptomatic, $10 \%$ to $30 \%$ may eventually develop a complication warranting surgical intervention [1]. Overall, approximately $1 \%$ of all patients with diverticular disease require surgical intervention [1].

*Address correspondence to this author at the Department of Surgery, Yonsei University College of Medicine, 50 Yonsei-ro Seodaemun-gu 120-752, Seoul, South Korea; Tel: +966503284959; Fax: +82-2-313-8289;

E-mail: sss_allah@hotmail.com

\section{INDICATIONS FOR SURGERY}

Emergency surgery is indicated in patients exhibiting signs of diffuse peritonitis, and deterioration/failure to improve with conservative therapy.

$\begin{array}{ll}\text { Absolute [1, 2] } \\ \text { - } & \text { Perforation } \\ \text { - } & \text { Obstruction } \\ \text { - } & \begin{array}{l}\text { Abscess (in patients with contraindications to surgery, } \\ \text { percutaneous drainage may be adequate to relieve } \\ \text { symptoms) }\end{array} \\ \text { - } \quad \text { Fistula } \\ \text { - } \quad \text { Clinical deterioration or failure to improve with } \\ \text { - } \quad \text { Redical therapy } \\ \text { - } \quad \text { Intractable symptoms } \\ \text { - } \quad \text { Inability to exclude carcinoma } \\ \text { Relative [1,2] } \\ \text { - } \quad \text { Symptomatic stricture } \\ \text { - } \quad \text { immunosupression } \\ \text { - } \quad \text { Right sided diverticulitis } \\ \text { - } \quad \text { Young patients }\end{array}$

The most recent controversies revolve around the indications for surgery in cases of uncomplicated and complicated diverticulitis (Table 1) [14].

\section{COMPLICATION OF THE DIVERTICULITIS}

Hinchey Classification1978 [14]

Stage I- pericolic or mesenteric abscess

Stage II-walled off pelvic abscess

Stage III-generalized purulent peritonitis

Stage IV-generalized fecal peritonitis 
Table 1. Indications for Surgery in Diverticulitis Cases

\begin{tabular}{|c|c|c|}
\hline Strictly Indicated by Available Literature & Available Literature Conflicting & $\begin{array}{c}\text { Previous Indications no Longer Supported Well by } \\
\text { Available Data }\end{array}$ \\
\hline \hline Diffuse peritonitis & $\begin{array}{c}\text { Following successful percutaneous drainage of } \\
\text { abscess }\end{array}$ & Uncomplicated first episode, even in patients aged $<50$ \\
\hline Free perforation & Uncomplicated; second and third episodes & \\
\hline Obstruction & & \\
\hline Stricture & & \\
\hline Fistula & & \\
\hline $\begin{array}{l}\text { Immunocompromized patients } \geq 4 \\
\text { uncomplicated episodes }\end{array}$ & \\
\hline
\end{tabular}

Stoma complication rate in literature varies widely, ranging from 10 to $70 \%$. It can be divided into early and late complications [3].

Among the early complications, the most common are peristomal skin irritation, infection, leakage, high output, bleeding and ischemia [3].

The most frequently reported late complications include dehydration, hernia, recurrence of the tumor or the disease like crohn's, nephrolithiasis and cholelithiasis $[1,3]$.

Prarstomal abscess is a rare type of stoma complication. However, diverticulitis at stoma site with abscess formation has not yet been reported in literature.

We report a rare case presented with prarstomal abscess caused by diverticulitis at the stoma site.

\section{CASE PRESENTATION}

The Chart review of 75 years old male patient is presented here with a change in stool caliper 6 years ago. He had a past history of hypertension, diabetes mellitus, atherosclerotic disease, atrial fibrillation, coronary artery disease and was smoking.

He had a tumor at $2 \mathrm{~cm}$ from anal verge and he underwent an abdominoperineal resection (Mile's) procedure.

In July 2011, the patient repated colostomy site pain, fever, and chills. Upon a physical examination, the temperature of 38.5, redness and tenderness at the lateral site of the stoma, loose stool at the bag and red color stoma were seen.

WBC 11,960.

Needle aspiration done and $15 \mathrm{cc}$ of greenish foul smelling pus was removed. Pigtail was inserted and broadspectrum antibiotic was given.

CT scan shows $4 \times 7 \mathrm{~cm}$ subcutaneous abscess at the lateral side of the stoma and distal colon shows diverticulitis (Figs. 1, 2, 3, 4).

On day 13 , the patient again witnessed a spike temperature of 38.1 and tenderness at the same site. Incision and drainage of the abscess site was conducted, $400 \mathrm{cc}$ of pus discharged and silastic drain was inserted.

The Colostomy was draining soft stool, ranging from 200 - 600 cc per day.

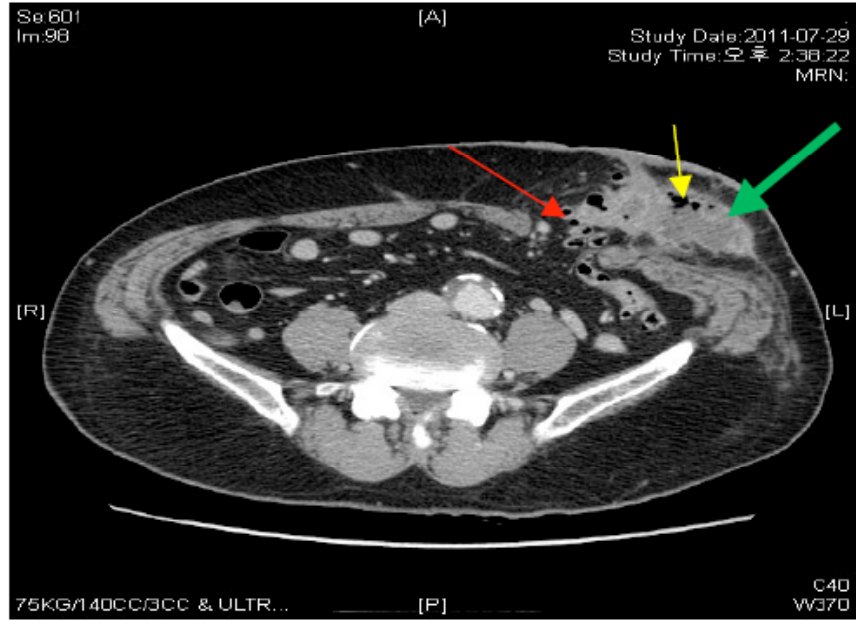

Fig. (1). Prarstomal abscess $4 \times 7 \mathrm{~cm}$ (green arrow), inflamed bowel segment at stoma site, multiple diverticulae ( red arrow), pocket of air (yellow arrow).

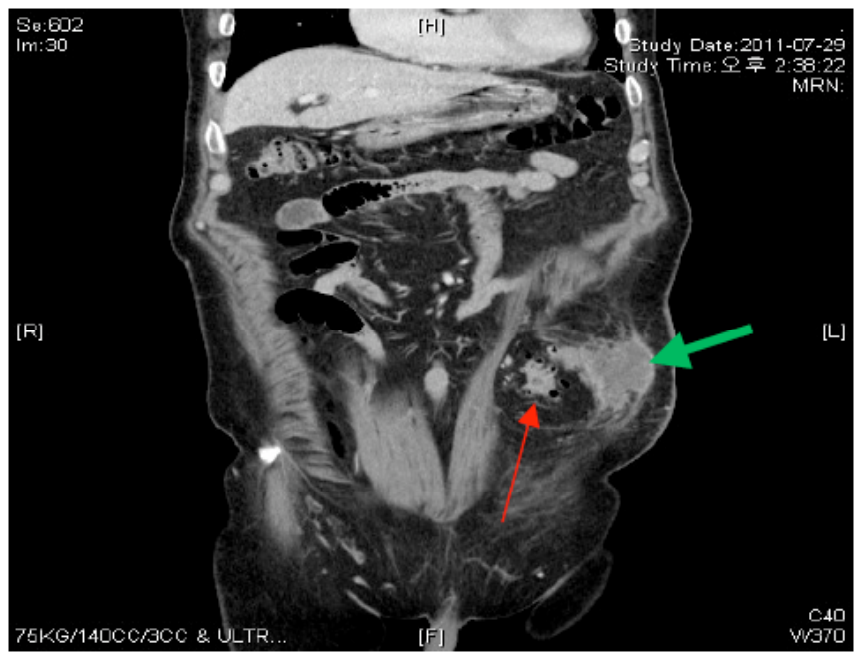

Fig. (2). Prarstomal abscess (green arrow) and inflamed bowel segment at stoma site and multiple diverticula (red arrow).

After 10 days of draining and antibiotics, the patient's remaining afebrile TAZOCIN (antibiotics) was stopped and the pig tail was removed on day 12 . 
CT scan was obtained on the same day showing resolution of the abscess and mild distal colon inflammation (Fig. $3)$.

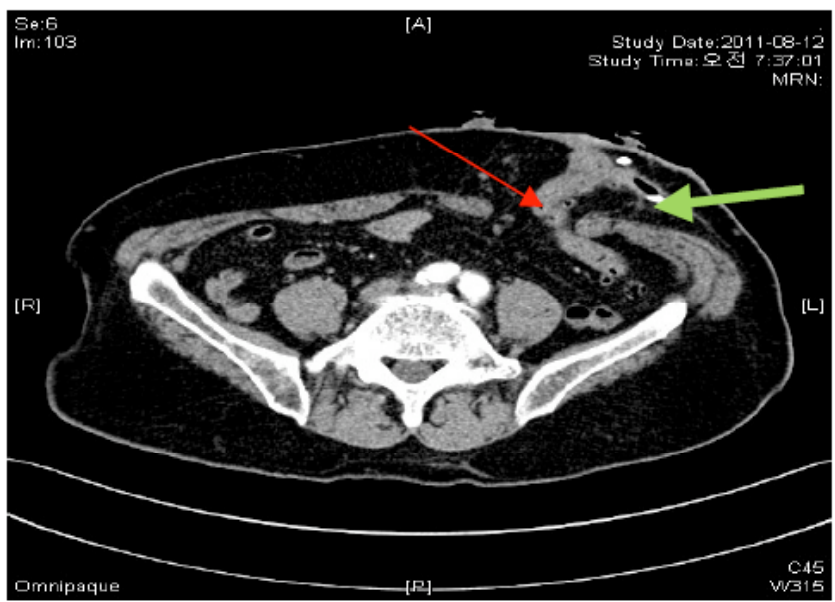

Fig. (3). Resolution of the abscess (green arrow) and mild distal colon inflammation (red arrow).

Patient was put on ciprofloxacin $200 \mathrm{mg}$ Intravenous and flagyl $500 \mathrm{mg}$ iv to target the diverticulitis and the abscess.

The patient was kept on soft diet and antibiotics for 13 days. Fever was subsiding and drainage of the pus was ceased.

CT scan was repeated and it shows resolved abscess and diverticulitis (Fig. 4).

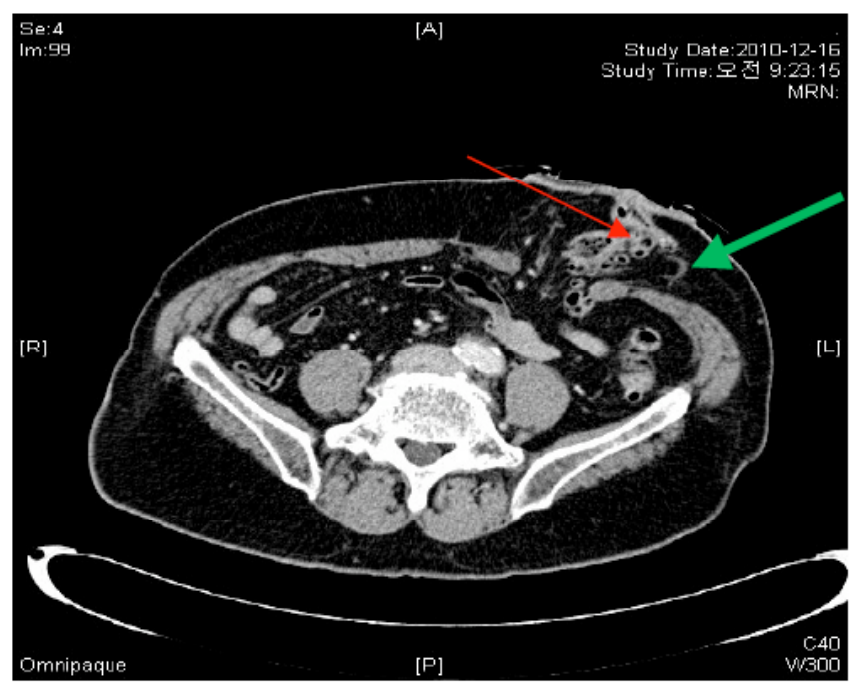

Fig. (4). Abscess resolved (green arrow) and inflammation disappeared from the diverticulae site (red arrow).

The patient was discharged home and planned for colonoscopy at a later time with repeated CT scan.

\section{COMMENT}

This patient represents a rare form of complicated diverticulitis at the stoma site after 6 years from its construction. The management was combined between surgical drainage and antibiotics. The predisposing factor for this diverticulitis could be multi factorial. Age of the patient, smoking, athero- sclerotic disease, and constipation could contribute to the presence of diverticulitis at this site.

However, the stoma site had the least pressure area where the diverticulitis were least likely to occur, specially when there were no previous diverticula in the colon before abdominoperineal resection. So, either this diverticulum was formed before the stoma formation or it developed after stoma had been performed from the other factors that we summarized it above.

In addition to these factors, stool impaction on the divirticulum can precipitate the presence of diverticulitis and a subsequent abscess formation from microperforation.

The risk of the recurrence of diverticulitis was reported to be varied. In case of diverticulitis associated with abscess data reported by Broderick - villa and others in 2005, long term nonoperative management and several small series report higher recurrence [15].

Moreover, surgical resection after the resolution of inflammation to the stoma and refashioning another stoma are still debatable issues. Whether the recurrence will occur at the same site or not is still unknown, so a follow up is recommended.

\section{CONFLICT OF INTEREST}

None declared.

\section{ACKNOWLEDGEMENT}

None declared.

\section{REFERENCES}

[1] Cameron JL. Current surgical therapy textbook. $9^{\text {th }}$ ed. 2009; pp. 166-70.

[2] Young-Fadock TM, Roberts PL, Spencer MP, Wolff BG. Colonic diverticular disease. Curr Prob Surg 2000; 37: 457-516.

[3] Beck DE, Roberts PL, Saclarides TJ, Senagore AJ, Stamos MJ, Waxner SD, Eds. The ASCRS textbook of colon and rectal surgery. $2^{\text {nd }}$ ed. Berlin: Springer 2011; pp. 375-394.

[4] Schwartz HA. Lower gastrointestinal side effects of nonsteroidal anti-inflammatory drugs. J Rheumatol 1981; 8: 952-4.

[5] Day TK. Intestinal perforation associated with osmotic slow release indomethacin capsule. BMJ 1983; 287: 1671-2.

[6] Aldoori WH, Giovannucci EL, Rimm EB, et al. A prospective study of diet and the risk of symptomatic diverticular disease in men. Am J Clin Nutr 1994; 60: 757-64.

[7] Manousos O, Day NE, Tzonou A, et al. Diet and other factors in the etiology of diverticulosis: an epidemiological study in Greece. Gut 1985; 26: 544-9.

[8] Papagrigoriadis S, Macey L, Bourantas N, et al. Smoking May associated with complications in diverticular disease. $\mathrm{Br} \mathrm{J}$ Surg 1999; 86: 923-6.

[9] Hart AR, Kennedy HJ, Stebbings WS, et al . How frequently do large bowel diverticula perforate? An incidence and cross-sectional study. Eur J Gastroenterol Hepatol 2000; 12: 661-5.

[10] Painter NS, Truelove SC. The intraluminal pressure patterns in diverticulosis of the colon. Part 2 : the effect of the morphine. Gut 1964; 5: 207-13.

[11] Hachigian MP, Honickman S, Eisenstat TE, et al. Computed tomography in the initial management of acute left-sided diverticulitis. Dis Colon Rectum 1992; 35: 1123-9.

[12] Tonnesen H, Engholm G, Moller H. Association between alcoholism and diverticulitis. Br J Surg 1999; 86: 1067-8. 
[13] Tayu ES, Prystowsky JB, Joehl RJ, et al. Acute diverticulitis. A complicated problem in the immunocompromised patient. Arch Surg 1991; 126: 855-8.

[14] Hinchey EJ, Schaal PG, Richards GK. Treatment of perforated diverticular disease of the colon. Adv Surg 1978; 12: 85-109.
[15] Broderick-Villa G, Bruchette RJ, Collins JC, et al. Hospitalization for acute diverticulitis does not mandate routine elective colectomy. Arch Surg 2004; 139: 1221.

Received: November 22, 2011

Revised: January 12, 2012

Accepted: January 13, 2012

(C) Al-Asari and Kim; Licensee Bentham Open.

This is an open access article licensed under the terms of the Creative Commons Attribution Non-Commercial License (http://creativecommons.org/licenses/by-nc/3.0/) which permits unrestricted, non-commercial use, distribution and reproduction in any medium, provided the work is properly cited. 